\title{
Leucocyte migration inhibition in liver disease
}

\author{
C. VERGANI, T. OLDONI, AND N. DIOGUARDI \\ From the Institute of Clinical Pathology, University of Milan, Milan, Italy
}

SYNOPSIS Clinical and histological features provide evidence that immunological reactions of the cell-mediated type are abnormal in some forms of chronic liver disease. By using the leucocyte migration test of Søborg and Bendixen (1967), a correlate of cellular hypersensitivity in vitro, the authors studied the production of the migration inhibitory factor by lymphocytes exposed to a fetal liver homogenate in 88 patients with acute and chronic liver disease. Abnormality of leucocyte migration was found in aggressive chronic hepatitis (inhibition in $67 \%$ of patients), cryptogenic cirrhosis (inhibition in $43 \%$, stimulation in $13 \%$ of patients), and primary biliary cirrhosis (stimulation in two, inhibition in two out of six patients).

The results are compatible with the hypothesis that cellular immune response to liver antigens is important in the pathogenesis of such diseases.

Cellular hypersensitivity to liver antigens may play a part in the pathogenesis of 'autoallergic' hepatitis (Doniach, 1970), namely, active chronic hepatitis, primary biliary cirrhosis, and certain cases of cryptogenic cirrhosis.

Histological evidence, very similar to that seen in the rejecting hepatic transplantation (Popper, 1971), lymphocyte stimulation in the presence of autologous liver (Tobias, Safran, and Schaffner, 1967), and clinical and biochemical responses to immunosuppressive therapy (Copenhagen Study Group for Liver Diseases, 1969; Cook, Mulligan, and Sherlock, 1971; Mistilis and Blackburn, 1967; Soloway, Summerskill, Baggenstoss, Geall, Gitnick, Elveback, and Schoenfield, 1972; Murray-Lyon, Stern, and Williams, 1973) all provide support for the postulated role of autoimmune processes.

The migration inhibitory factor (MIF) test is thought to be the best correlate in vitro of cellular immune responses in 'vivo (David and David, 1972). For these reasons, we carried out MIF tests in patients with acute and chronic liver diseases, using the leucocyte migration inhibition technique of Søborg and Bendixen (1967).

\section{Materials and Methods}

PATIENTS AND CONTROLS

Eighty-eight patients with liver disease were investigated, divided on the basis of clinical and histological data (De Groote, 1968), into acute hepatitis (13 patients), chronic persistent hepatitis
(11 patients), chronic aggressive hepatitis (24 patients), cryptogenic cirrhosis (23 patients), alcoholic cirrhosis (11 patients), and primary biliary cirrhosis (6 patients).

A normal control group consisted of 24 healthy subjects.

THE LEUCOCYTE MIGRATION INHIBITION TEST The technique of Søborg and Bendixen with minor modifications was employed.

Thirty $\mathrm{ml}$ of peripheral venous blood mixed with 2000 IU of preservative-free heparin and $6 \mathrm{ml}$ of Plasmagel (Roger-Bellon, Paris) was allowed to sediment at $37^{\circ} \mathrm{C}$ for one hour. The WBC-rich supernatant was centrifuged at $150 \times g$ for 10 minutes and the cell pellet washed three times in Hank's balanced salt solution (HBSS) calcium and magnesium free (Grand Island Biological $\mathrm{Co}$, Grand Island, NY).

The washed cells were resuspended in Eagle's minimum essential medium (MEM) with $25 \mathrm{mM}$ Hepes buffer (Grand Island Biological Co, Grand Island, NY) supplemented with $1 \% 200 \mathrm{mM}$ glutamine, penicillin $100 \mathrm{U} / \mathrm{ml}$, streptomycin 100 $\mu \mathrm{g} / \mathrm{ml}$, and fungizone $0.25 \mu \mathrm{g} / \mathrm{ml}$.

The leucocyte suspension was centrifuged at $350 \times g$ for 10 minutes in microhaematocrit capillary tubes sealed at one end with non-toxic plastiline.

Each capillary tube was cut at the fluid-cell interface and placed in a Teflon ring chamber secured in place by silicone wax. About $1 \mathrm{ml}$ medium with or without antigen was added to the chamber. 
The chamber was placed in an incubator at $37^{\circ} \mathrm{C}$ and the leucocytes were allowed to migrate for 20 hours.

The areas of migration were projected from a projection microscope onto thick paper, outlined, cut out and weighed.

Each test was run in quadruplicate.

Typical results are presented in figure 1 .

The percentage of the migration or migration
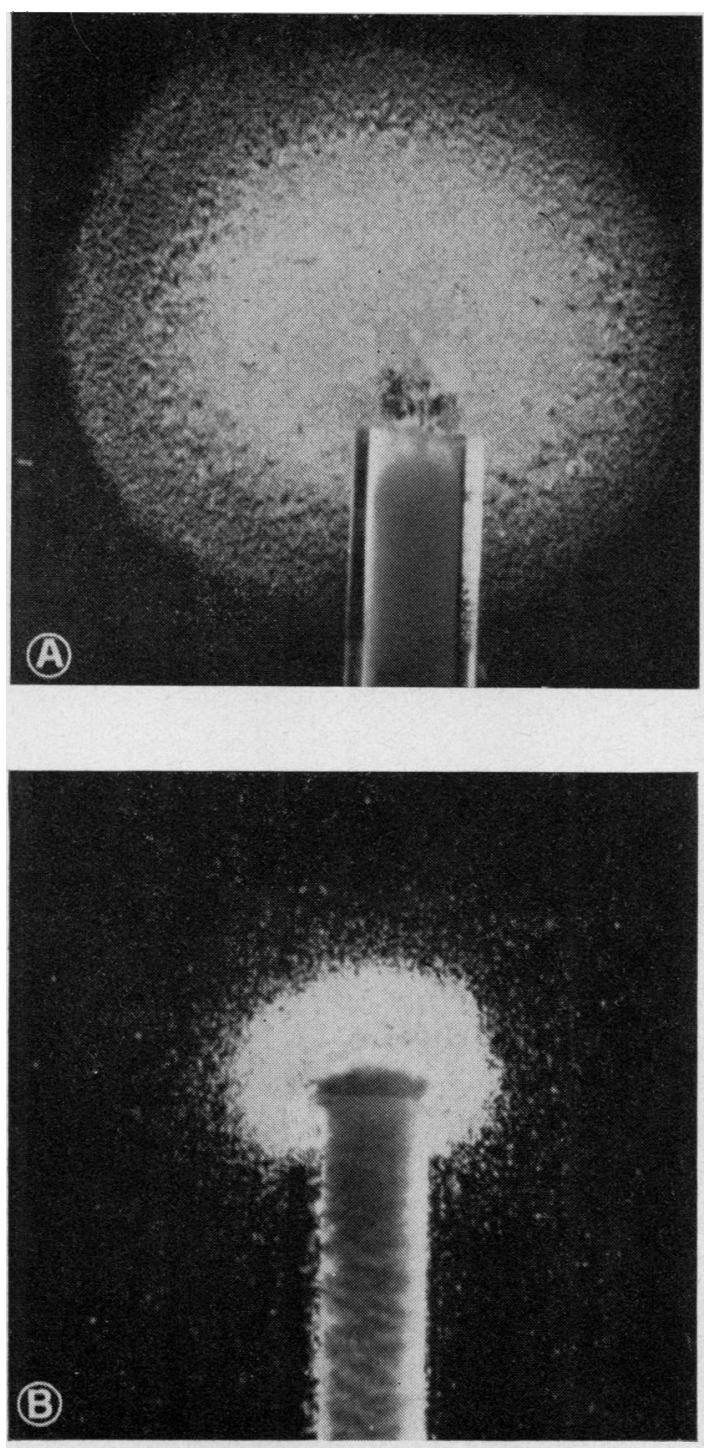

Fig 1 Migration of leucocytes from a patient with chronic aggressive hepatitis: $A-n o$ antigen added; $B$-with antigen. index (MI) was calculated according to the following formula:

$$
\text { MI }=\frac{\text { Average area with antigen }}{\text { Average area without antigen }} \times 100
$$

The tests were found to be reproducible both with respect to the coefficient of variation $(8.3 \%)$ and also when tests were repeated three times on the same patient within one week (MI 94.2\%, 94.8\%, $92.5 \%$ ).

\section{LIVER ANTIGENS}

Fetal liver obtained at necropsy was used. The liver, washed many times in HBSS, was homogenized and centrifuged at $1500 \times g$ for five minutes. The supernatant was distributed in small aliquots and stored at $-80^{\circ} \mathrm{C}$.

Antigen added to the chamber was adjusted to produce a final concentration of $400 \mu \mathrm{g}$ of protein, as determined by microKjeldhal method, per $\mathrm{ml}$ of tissue culture medium.

Levels of serum $\gamma$ globulin, glutamic-oxalacetic, and glutamic-pyruvic transaminases, and total bilirubin were determined by standard methods.

Hepatitis B antigen (HB-Ag) was detected by counterimmunoelectrophoresis.

\section{Results}

Our results in normal subjects and in patients with acute and chronic liver diseases are shown in figure 2 .

The MI range in healthy controls was from 87 to $113 \%$. Significant abnormality in the migration index was found, with few exceptions, only in chronic aggressive hepatitis (inhibition in 16 patients, $67 \%$ ), in cryptogenic cirrhosis (inhibition in 10, $43 \%$; stimulation in three patients, $13 \%$, and in primary biliary cirrhosis (inhibition in two, stimulation in two out of six patients).

No correlation could be detected between MIF test results in respect of either the serum $\gamma$ globulin, glutamic-oxalacetic and glutamic-pyruvic transaminases, and total bilirubin level or the presence of hepatitis $B$ antigen.

\section{Discussion}

Our data agree with other results (Brostoff, 1970; Smith, Golding, Eddleston, Mitchell, Kemp, and Williams, 1972; Miller et al, 1972) and provide evidence that cell-mediated immunity is implicated in some forms of chronic liver disease.

Not all the patients with 'autoallergic' hepatitis have lymphocytes producing MIF when exposed to liver antigens, probably because several different 


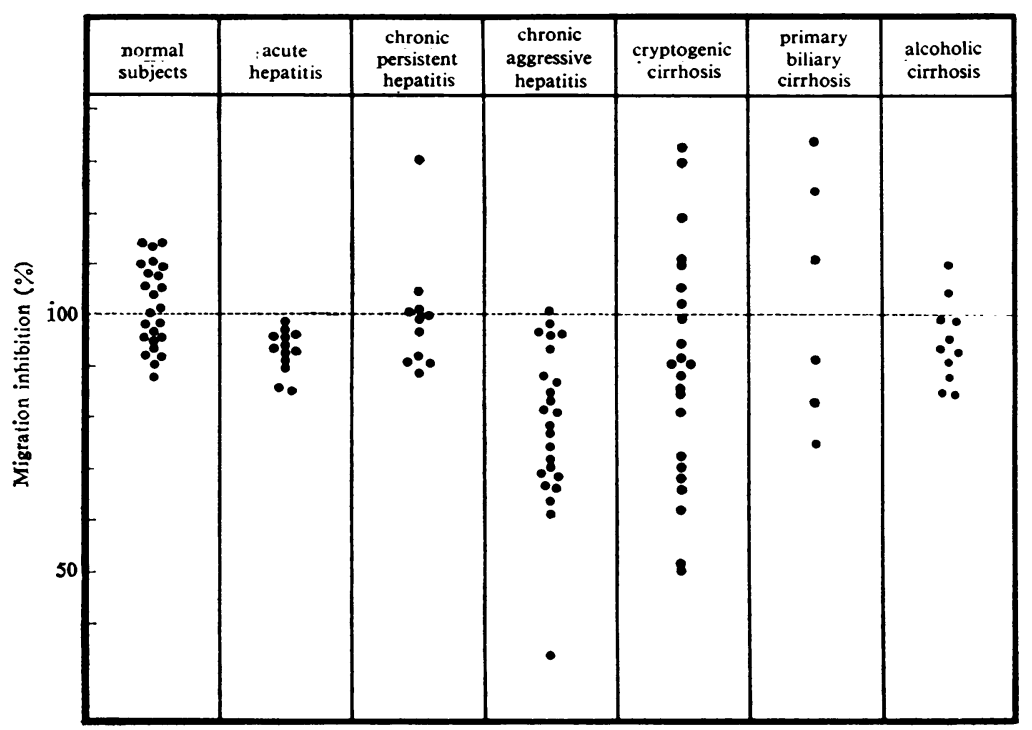

Fig 2 Leucocyte migration test in normal subjects and in patients with acute hepatitis, chronic persistent hepatitis, chronic aggressive hepatitis, cryptogenic cirrhosis, primary biliary cirrhosis, alcoholic cirrhosis.

pathogenetic processes underlie these conditions. In this respect, active chronic hepatitis has been considered a 'syndrome' (Mistilis and Blackburn, 1970; Bulkley, Heizer, Goldfinger, and Isselbacher, 1970; Doniach, Walker, Roitt, and Berg, 1970).

In cryptogenic cirrhosis, which is supposed to be the natural evolution of active chronic hepatitis (Dudley et al, 1972), inhibition of migration is less frequent $(43 \%)$ than in the latter $(67 \%)$. This may be related to the fact that fibrosis isolates parenchyma in such a way that liver antigens are prevented from coming into contact with immunocompetent cells. Stimulation found in three patients with cryptogenic cirrhosis and in two patients with primary biliary cirrhosis may be regarded, according to Søborg (1968), as a correlate in vitro of weak sensitization in vivo. In primary biliary cirrhosis this is probably due to the fact that in the early stages of the disease the immune attack is directed against bile duct antigens and only later against hepatocellular antigens (Miller et al, 1972).

Immunological abnormalities in primary biliary cirrhosis will be better defined when bile duct antigens can be obtained.

In our opinion the MIF test has proved to be a diagnostically useful tool, especially when liver biopsy is not feasible because of coagulation disorders. Actually it can segregate a large proportion of patients with aggressive chronic hepatitis, cryptogenic cirrhosis, or primary biliary cirrhosis. The effect of immunosuppressive therapy on the MI and consequently the use of the migration inhibitory factor test for the titration of therapy remain to be determined.

\section{References}

Brostoff, J. (1970). Migration inhibition studies in human diseas Proc. roy. Soc. Med., 63, 905-906.

Bulkley, B. H., Heizer, W. D., Goldfinger, S. E., and Isselbacher, K. J. (1970). Distinctions in chronic active hepatitis based on circulating hepatitis-associated antigen. Lancet, 2, 1323-1326.

Cook, G. C., Mulligan, R., and Sherlock, S. (1971). Controlled prospective trial of corticosteroid therapy in active chronic hepatitis. Quart. J. Med., 40, 159-185.

Copenhagen Study Group for Liver Diseases (1969). Effect of prednisone on the survival of patients with cirrhosis of the liver. Lancet, 1, 119-121.

David, J. R., and David, R. R. (1972). Cellular hypersensitivity and immunity. Progr. Allergy, 16, 398-407.

De Groote, J., Gedigk, P., Popper, H., Scheuer, P. J., Thaler, H., Wepler, W., Desmet, U. J., Korb, G., Poulsen, H., Schmid, M., and Vehlinger, E. (1968). A classification of chronic hepatitis. Lancet, 2, 626-628.

Doniach, D. (1970). The concept of an 'autoallergic' hepatitis. Proc. roy. Soc. Med., 63, 527-531.

Doniach, D., Walker, J. G., Roitt, I. M., and Berg, P. A. (1970). 'Autoallergic' hepatitis. New Engl. J. Med., 282, 86-88.

Dudley, F. J., Scheuer, P. J., and Sherlock, S. (1972). Natural history of hepatitis associated Antigen-positive chronic liver disease. Lancet, 2, 1388-1393.

Miller, J., Smith, M. G. M., Mitchell, C. G., Reed, W. D., Eddleston, A. L. W. F., and Williams, R. (1972). Cell-mediated immunity of to a human liver-specific antigen in patients with active chronic hepatitis and primary biliary cirrhosis. Lancet, 2, 296-297.

Mistilis, S. P., and Blackburn, C. R. B. (1967). The treatment of $N$ active chronic hepatitis with 6-mercaptopurine and azathio- $\omega$ prine. Aust. Ann. Med., 16, 305-311.

Mistilis, S. P., and Blackburn, C. R. B. (1970). Active chronic hepatitis. Amer. J. Med., 48, 484-495.

Murray-Lyon, I. M., Stern, R. B., and Williams, R. (1973). Controlled trial of prednisone and azathioprine in active chronic hepatitis. Lancet, 1, 735-737.

Popper, H. (1971). Morphological and immunological studies on $\underset{T}{T}$ chronic aggressive hepatitis and primary biliary cirrhosis. In Immunology of the Liver, edited by M. Smith and R. Williams, pp. 17-27. Heinemann, London. 
Smith, M. G. M., Golding, P. L., Eddleston, A. L. W. F., Mitchell, C. G., Kemp, A., and Williams, R. (1972). Cell mediated responses in chronic liver diseases. Brit. med. J., 1, 527-530.

Søborg, M. (1968). In vitro migration of peripheral human leucocytes in cellular hypersensitivity. Acta med. scand., 184, 135-139.

Søborg, M., and Bendixen, G. (1967). Human lymphocyte migration as a parameter of hypersensitivity. Acta med. scand., 181, 247-256.
Soloway, R. D., Summerskill, W. H. J., Baggenstoss, A. H., Geall, M. G., Gitnick, G. L., Elveback, L. R., and Schoenfield, L. J. (1972). Clinical, biochemical and histological remission of severe chronic active liver disease: a controlled study of treatments and early prognosis. Gastroenterology, 63, 820-833.

Tobias, H., Safran, A. P., and Schaffner, F. (1967). Lymphocyte stimulation and chronic liver disease. Lancet, 1, 193-195. 